\section{Seasonal Changes in Systemic Volume Overload Are to Be Considered}

\section{To the Editor:}

We read with a great interest the recent paper by Hirai et al entitled "Clinical Scenario 1 Is Associated With Winter Onset of Acute Heart Failure". ${ }^{1}$ A seasonal variation in acute heart failure $(\mathrm{AHF})$ and its risk, particularly during the winter period, remains a valid clinical question, and the authors have stated that the lack of loop diuretics could predispose patients to decompensation. We would like to add several comments on their discussion of this topic.

First of all, the original clinical scenario by Mebazaa et al does not recommend classification based solely on systolic blood pressure. ${ }^{2}$ A patient's clinical status, such as the degree of systemic volume overload (eg, peripheral edema), is to be considered. Clearly, this is of importance when agents for volume reduction (eg, loop diuretics) are considered. ${ }^{3,4}$ In our own data on 1,882 consecutive AHF patients registered in the West Tokyo Heart Failure Registry (WET-HF; from April 2006 to December 2013), we observed both higher frequency of high blood pressure on presentation (systolic blood pressure $\geq 140 \mathrm{mmHg}$; Figure A), as well as the clinical sign of peripheral edema during winter (Figure B). Interestingly, the reduction in body weight during hospitalization was similar between different seasons. We believe that information on detailed clinical parameters, rather than sole classification based on systolic blood pressure, would be beneficial to understand the results and conclusion by Hirai et al that "only a lack of loop diuretic use was a contributing factor for winter onset of $\mathrm{AHF}$ in CS1 patients, whose treatment was usually vasodilators".

We would also like to emphasize that the current ACCF/ AHA and ESC guidelines do not recommend the use of "clinical scenario" at this time, ${ }^{3,4}$ because the prognostic and clinical significance of clinical scenarios has not been validated. This further underscores the need for a validated hemodynamic model, such as blood pressure, to validate these authors' hypothesis.

\section{Disclosures}

No conflicts of interest exist in this study.

\section{References}

1. Hirai M, Kato M, Kinugasa Y, Sugihara S, Yanagihara K, Yamada $\mathrm{K}$, et al. Clinical scenario 1 is associated with winter onset of acute heart failure. Circ J 2015; 79: 129-135.

2. Mebazaa A, Gheorghiade M, Pina IL, Harjola VP, Hollenberg SM, Follath F, et al. Practical recommendations for prehospital and early in-hospital management of patients presenting with acute heart failure syndromes. Crit Care Med 2008; 36: S129-S139.

3. McMurray JJ, Adamopoulos S, Anker SD, Auricchio A, Bohm M, Dickstein K, et al. ESC guidelines for the diagnosis and treatment of acute and chronic heart failure 2012: The Task Force for the Diagnosis and Treatment of Acute and Chronic Heart Failure 2012 of the European Society of Cardiology: Developed in collaboration with

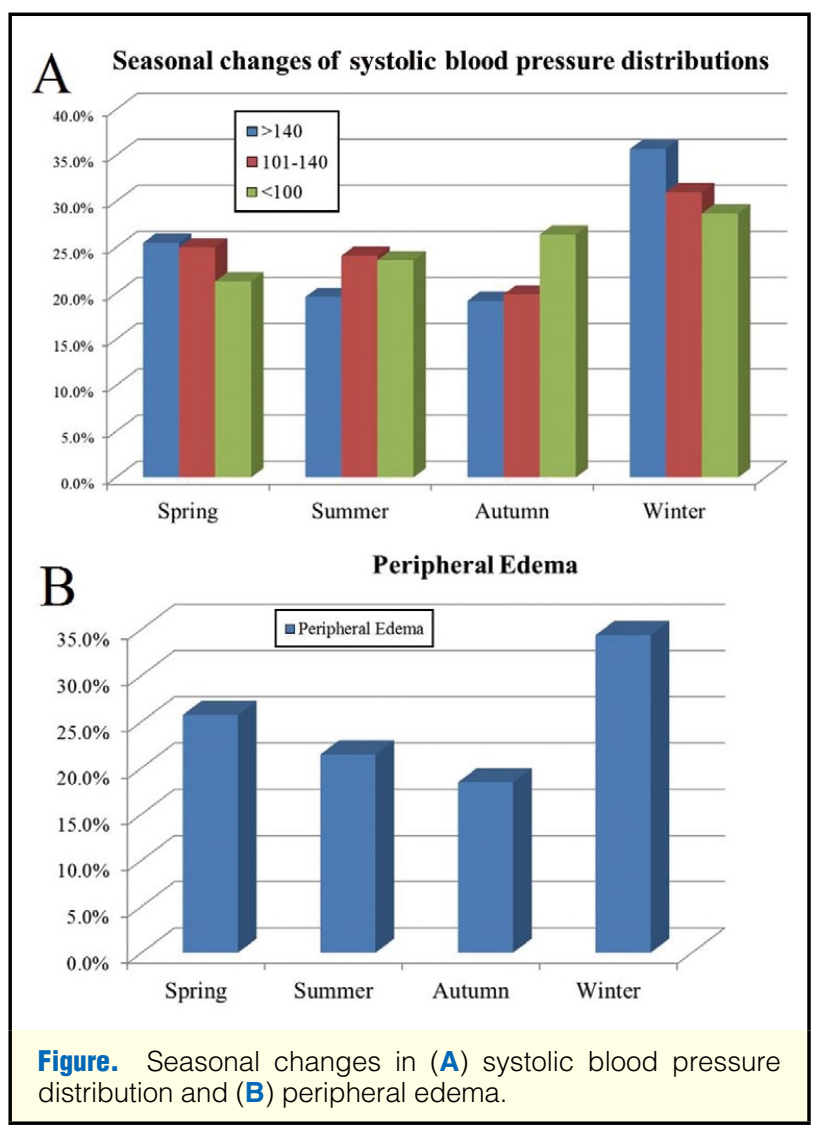

the Heart Failure Association (HFA) of the ESC. Eur Heart J 2012; 33: $1787-1847$.

4. Yancy CW, Jessup M, Bozkurt B, Butler J, Casey DE Jr, Drazner $\mathrm{MH}$, et al. 2013 ACCF/AHA guideline for the management of heart failure: A report of the American College of Cardiology Foundation/ American Heart Association Task Force on Practice Guidelines. $J$ Am Coll Cardiol 2013; 62: e147-e239, doi:10.1016/j.jacc.2013. 05.019 .

Atsushi Mizuno, MD

Department of Cardiology, St. Luke's International Hospital, Tokyo, Japan

Shun Kohsaka, MD

Yasuyuki Shiraishi, MD

Department of Cardiology, Keio University School of Medicine, Tokyo, Japan

Ayumi Goda, MD, PhD

Division of Cardiology, Kyorin University School of Medicine, Tokyo, Japan

Tsutomu Yoshikawa, MD

Department of Cardiology, Sakakibara Heart Institute, Tokyo, Japan (For the West of Tokyo Heart Failure Registry Investigators)

(Released online January 22, 2015) 